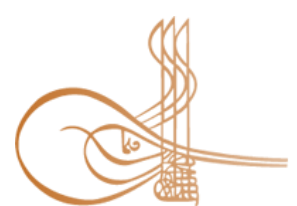

www.turkishstudies.net/language

\section{Turkish Studies - Language and Literature}

\author{
eISSN: 2667-5641
}

Research Article / Araștırma Makalesi

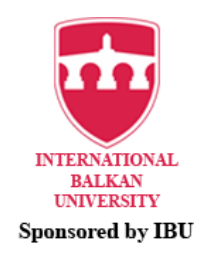

Sponsored by IBU

\title{
Avusturya İlkokullarında Arapça Anadil Öğretimi
}

\author{
Arabic Mother Language Teaching in Austrian Primary School
}

\author{
Hüseyin Demir*
}

\begin{abstract}
Most of the children of Arab origin, Austrian citizens or Arab immigrants living in Austria, one of the Central European countries, acquire Arabic as their mother tongue at home; from kindergarten, they learn German as a second language in schools. Mother language education makes a significant contribution to children's self-confidence, the development of a personality and identity formation, and the opportunity to transform their cultural ties with their parents or their countries of origin into a stronger structure. Increasing the educational level of students, needs orientation, skill diversity, development of opportunity and gender equality are among the primary goals of the Austrian education system. In Austria, German is the official language of instruction and good language skills are essential not only for German lessons but also for a student's school success. For this reason, giving Arabic mother language lessons as an elective course to Arab students in Austrian primary schools by the Austrian Ministry of Education will cause the student to master two languages and thus have self-confidence thanks to the support of mother language education. This selfconfidence will also be reflected in the academic success of the student. This study covers the importance, historical development of Arabic mother tongue-based courses and how the education and training of these courses are given to the students of Arab Austrians or Arab immigrants, who are between the ages of 6 and 10 studying at public primary schools within the framework of the Austrian state language policies especially in the capital Vienna and seven other states, to learn German better.
\end{abstract}

Structured Abstract: Austria, one of the European countries that went to restructuring after the World War II, brought the family and children with them due to the prolongation of their stay. After that, Austrian schools - especially primary and secondary schools in metropol cities - came face to face with foreign children of the guest-worker families for the first time. The first mother language lessons started under the bilateral agreements of the countries between 1972 and 1991 in the state of Vorarlberg in the west of Austria under the name of an additional course in Serbian-Croatian, Slovenian and Turkish, and then in the other eight provinces of Austria with different mother languages. Lessons started to be given. Teachers who gave language lessons were financed by the countries they came from based on the principle of rotation, after nearly four or five years, they returned to their home countries and were sent by their teachers. The aim of the teachers was to develop the students' mother language, to provide a cultural connection by informing them about their own countries, and to help them continue their education without difficulty after returning to their countries. Afterwards, it was observed that many guest workers had no intention of returning to their countries in the near future and most of the children were born in Austria, and by the beginning of 1990, the bilateral agreements between the countries ended and the teachers of the mother language lessons were assigned to the schools by the Austrian

\footnotetext{
* Dr. Öğr. Üyesi, Bartın Üniversitesi, Edebiyat Fakültesi, Çeviribilim Bölümü

Asst. Prof. Dr. Bartın University, Faculty of Letters, Department of Translation Studies

ORCID 0000-0003-3302-5741

hueseyindemir@hotmail.com

Cite as/ Atıf: Demir, H. (2020). Avusturya ilkokullarında Arapça anadil öğretimi. Turkish Studies - Language, 15(3),

1149-1162. https://dx.doi.org/10.47845/TurkishStudies.45348

Received/Geliş: 15 July/Temmuz 2020

Checked by plagiarism software

Accepted/Kabul: 15 September/Eylül 2020

Published/Yayın: 30 September/Eylül 2020

Copyright (C) INTAC LTD, Turkey

CC BY-NC 4.0
} 
Ministry of Education. In this study, where descriptive research and literature review method is used, Arabic mother language lessons given to students of Arab origin have been examined in the context of Austrian language policies, based on the importance of second language acquisition (German) in Austrian primary schools. It was aimed to attend Arabic language courses in order to ensure that children of Austrian citizens or Arab immigrants feel confident, develop a personality and identity formation, and find the opportunity to transform their cultural characteristics into a more solid structure with their parents or countries they have come from. Arabic language teaching began to be implemented in the 1990 s and has become widespread in educational institutions in eight provinces of Austria. According to the latest statistical data, Turkish was ranked first among 26 different mother tongue courses, and second place was Bosnian / Croatian / Serbian and third place was Arabic. A total of 3129 students, 13 male teachers and 19 female teachers, 32 teachers in total, have been taught Arabic language at all educational institutions, including 2273 elementary school students, 570 secondary school students and 286 students attending Arabic language classes. Of the 32 teachers, 2 are Egyptian, 1 is Moroccan, 5 are Syrian, 1 is Tunisian and 23 are of Arab origin with Austrian citizenship. Arabic mother language lessons, 1 teacher for 86 students, 11 teaching hours in 3 primary schools in Kärnten state, 3 teachers for 189 students, 26 teaching hours in 12 primary schools in the state of Niederösterreich, 1 teacher for 132 students, 27 teaching hours in 7 primary schools in the state of Oberösterreich, 3 teachers for 176 students, 24 teaching hours in 8 primary schools in Salzburg state, 2 teachers for 300 students, 35 teaching hours in 11 primary schools in Styria, 1 teacher for 72 students, 12 teaching hours in 3 primary schools in Tyrol, 16 teachers in Vorarlberg 2 teachers were given to 211 students, 23 teaching hours, and 19 teachers were given to 1960 students, 410 teaching hours at 50 primary schools in the state of Wien. Efforts have been made to address the cultural differences, misunderstandings and insecurities included in the education curriculum in Arabic primary language lessons given in Austrian primary schools, to assist in the formation and integration of mother language teaching, and the development of biculturalism, the development and consolidation of bilingualism. The teaching of Arabic as a mother tongue has not yet been fully satisfactorily integrated into school life because of the conditions that are not sufficient, even though other mother language teaching has an important place in the education curriculum and bilingualism is a principle to be made. These reasons for this are that the number of student enrollments is high, the main language course is a non-binding applied elective course, the lessons are given in the afternoon, the lesson hours are not given, the report card is not given, the reputation against the mother tongue is less, the learning of normal school lessons is more prominent. Many parents who know the meaning and importance of their mother language education by taking private lessons in learning their mother language due to the fact that their teacher salaries are low, their mother language teachers are not better integrated in school life, parents do not have much knowledge about mother language education, they are trying to overcome this shortcoming.

Keywords: Arabic Teaching, Mother Language, Primary School, Austria, Austrian Educational System.

Öz: Orta Avrupa ülkelerinden birisi olan Avusturya'da yaşayan Arap kökenli Avusturya vatandaşı veya Arap göçmen çocukların çoğu, evde anadili olarak Arapçayı edinmekte olup; anaokulundan itibaren ikinci bir dil olan Almancayı da okullarda öğrenmektedirler. Anadili öğrenimi çocukların kendilerine özgüven duymalarına, bir kişilik ve kimlik oluşumunun geliştirilmesine ve ebeveynlerinin veya gelmiş oldukları ülkeleri ile de kültürel bağlarının daha sağlam bir yapıya dönüştürme imkânını bulabilmelerine önemli bir katkı sağlamaktadır. Öğrencilerin eğitim düzeyinin arttırılması, ihtiyaç yönelimi, beceri çeşitliliği, fırsat ve cinsiyet eşitliliğin geliştirilmesi Avusturya eğitim sisteminin öncelikli hedefleri arasındadır. Avusturya'da Almanca, resmi eğitim dili olup iyi derecede dil becerilerine sahip olmak sadece Almanca dersleri için değil bir öğrencinin okul başarısı için de oldukça önemlidir. Bu sebepledir ki Avusturya Milli Eğitim Bakanlığı tarafından Avusturya ilkokullarında Arap kökenli öğrencilere seçmeli ders olarak Arapça anadil derslerinin verilmesi, öğrencinin anadil eğitimi desteği sayesinde iki dile hakim olmasına ve dolayısıyla kendine özgüven duymasına sebep olacaktır. Bu özgüven de öğrencinin akademik başarısına yansıyacaktır. Bu çalışmanın amacı Avusturya devleti dil politikaları çerçevesinde ülkenin başkenti Viyana başta olmak üzere diğer yedi eyalette bulunan devlet ilkokullarında eğitim gören 6 ile 10 yaş arasındaki Arap kökenli Avusturya vatandaşı veya Arap göçmen öğrencilerin Almancayı daha iyi öğrenebilmeleri için verilen Arapça anadil derslerinin önemini, tarihi gelişimini, derslerinin eğitimi ve öğretimini kapsamaktadır.

Anahtar Kelimeler: Arapça Öğretimi, Anadil, İlkokul, Avusturya, Avusturya Eğitim Sistemi. 


\section{Giriş}

İyi eğitimli, verimli ve nitelikli bir nüfus Avusturya'nın sosyal ve ekonomik refahı için temel öneme sahiptir. Eğitim, bireylerin sosyal, ekonomik ve kültürel yaşama etkin bir şekilde katılabilecek bilgi, tutum ve becerilere sahip olmalarını sağlamada önemli bir faktördür. Öğrencilerin eğitim düzeyinin arttırılması, ihtiyaç yönelimi, beceri çeşitliliği, fırsat ve cinsiyet eşitliliğin geliştirilmesi Avusturya eğitim sisteminin öncelikli hedefleri arasındadır. Avusturya'da Almanca, resmi eğitim dili olup iyi derecede dil becerilerine sahip olmak sadece Almanca dersleri için değil bir öğrencinin okul başarısı için de oldukça önemlidir. Avusturya'da yaşayan Arap kökenli Avusturya vatandaşı veya Arap göçmen çocukların çoğu, evde anadili olarak Arapçayı edinmekte olup anaokulundan itibaren ikinci bir dil olan Almanca dilini de öğrenmektedirler. Çocukların kendilerine özgüven duymaları, bir kişilik ve kimlik geliştirmeleri gelmiş oldukları ülkeleri ile de kültürel özelliklerini daha sağlam bir yapıya dönüştürme imkânını bulabilmeleri için, anadili öğrenimi çok büyük bir önem taşımaktadır. 5 yaşında başlayan zorunlu anaokulu eğitiminden sonra çocukların eğitim için ilk adımlarını attıkları ilkokullarda anadillerinin daha iyi bir şekilde gelişmesinin sağlanması, farklı Avrupa ülkelerinde göçmen çocuklara anadil öğretimi kaldırılması söz konusu iken Avusturya'da eğitimin bütün aşamalarında çocuklara anadili öğretimi devlet tarafindan finanse edilerek desteklenmektedir (Guus ve Yağmur, 2013; Cillia, 2006; Das österreichische Schulsystem, 2020).

\section{Avusturya'da Yabancılara Anadillerinin Öğretiminin Önemi ve Tarihsel Gelişimi}

Göçmen kökenli çocukların anadillerinin yeterli olmaması ve ileriki süreçte anadillerini öğrenemezlerse genel bilişsel becerilerin gelişmesinin yanı sıra hem anadilini hem de ikinci dil ediniminde de istenilen başarıyı elde etmelerinde sorunlar yaşayabilirler. Bunun sonucu, öğrencinin dil becerileri ne tam anlamıyla gelişebilir ne de bu anadilde sosyalleşmedeki eksiklikler yüzünden diğer dillerin öğrenimi sağlanabilir (BMBWF, 2002).

Anadili edinimi genellikle öğrencinin bilişsel ve sosyal gelişiminde çok önemli olup düşünce süreçlerinin oluşmasında ve yapılanmasında ana etkenlerden sayılır. Bireyin kelime hazinesi ne kadar geniş olursa o kadar çok algı, anlayış ve bilişsel farklılıklar ortaya çıkar. Dolayısıyla çocuğun anadilini kullanmasındaki özgüven, öğreneceği diğer dil olan burada söz konusu olan Almanca dilini ve diğer derslerinde de göstereceği başarının sağlanmasına çok büyük bir katkı sağlayacağı düşünülmektedir. Bu yüzden çocuğun anadilinin daha da gelişmesinin sağlanması ancak anadilini öğretecek uzman bir öğretmen tarafından gerçekleşebilir (Cillia, 2006).

İkinci Dünya Savaşından sonra yeniden yapılanmaya giden Avrupa ülkelerinden biri olan Avusturya’ya, 1960'lı yıllarda işgücü sıkıntısı sebebiyle getirtilen konuk işçiler, daha sonra kalma sürelerinin uzamasından dolayı yanlarında ailelerini ve çocuklarını da getirdiler. Bundan sonra, Avusturya okulları - özellikle büyük şehirlerdeki ilkokul ve ortaokullar - ilk kez konuk işçi ailelerinin çocuklarıyla karşı karşıya geldi. İlk anadil dersleri ülkelerin ikili anlaşmalar çerçevesinde 1972 1991 yılları arasında Avusturya'nın batısında yer alan Vorarlberg eyaletinde Sırpça-Hırvatça, Slovence ve Türkçe dillerinde ek bir ders adı altında başlamış daha sonra farklı anadillerle birlikte Avusturya'nın diğer sekiz eyaletlerinde de anadil dersleriyle devam etmiştir. Anadil derslerini veren öğretmenler rotasyon prensibine göre geldikleri ülkeler tarafindan finanse edilip yaklaşık dört veya beş yıl kaldıktan sonra kendi ülkelerine dönerek onların yerine başka öğretmenler ülkeleri tarafindan gönderiliyordu. Öğretmenlerin amacı, öğrencilerin anadillerini geliştirmek, öğrencileri kendi ülkeleri hakkında bilgilendirerek kültürel bir bağın oluşmasını sağlamak ve daha sonra bu öğrenciler ülkelerine döndükten sonra zorlanmadan eğitimlerine devam etmelerine yardımc1 olmaktı. Daha sonra birçok konuk iş̧̧inin yakın gelecekte ülkelerine dönmek gibi bir niyetleri olmadığı ve çocukların birçoğu Avusturya'da dünyaya geldikleri gözlemlenerek 1990 yılı başları itibariyle ülkeler arasında yapılan ikili anlaşmalar son bularak bundan sonraki süreçte anadil dersi öğretmenleri, Avusturya Milli Eğitim Bakanlığı tarafından görevlendirilmiştir (BMBWF, 2012a; Fleck, 2002; Çınar, 1998; Cinar\&Davy 1998). 


\section{Avusturya'da İlkokul Süreci}

Avusturya'da altı yaşına gelmiş bir çocuğun zorunlu olarak 4 senelik ilkokul eğitimi başlamakla beraber özel okullar (karma ve paralı) veya devlet okulları (karma ve parasız) arasından öğrenci aileleri tarafından bir seçim yapılmaktadır. Bütün öğrencilere eğitim süresince zihinsel, duygusal, bedensel ve sosyal becerilerinin ve yeteneklerinin ortaya çıarılması teşvik edilmektedir. Dört sene süren ilkokul eğitimi sonunda dijital çağda değişen bir toplumda kendilerine güvenen genç bireylerin yetişmeleri sağlanmaktadır (Das österreichische Schulsystem, 2020; Archan ve Mayr, 2006; Avusturya'nın Eğitim Sistemi, 2020).

Milli Eğitim Müdürlükleri tarafından 6 yaşını dolduran çocukların adreslerine en yakın ilkokula kayıt yaptırmak için gerekli olan evraklar ve kayıt tarihlerini içeren bir yazı öğrenci velilerine gönderilmektedir. Ayrıca 2009 yılı itibariyle Avusturya'da 5 yaşını dolduran çocukların haftada en az 20 saat anaokuluna gitme zorunluluğu getirilmiş ve ilkokula kayıt yaptırırken her bir çocuğun gelişim süreçlerini gösteren anaokulundan verilen anaokulu dosyasını da yanlarına almaları istenmiştir. Başvuru yapılırken çocuğun okula hazır olup olmaması oyun biçiminde hazırlanan dilsel, davranış, sosyal ve duygusal faaliyetleri öğretmenler tarafindan gözden geçirilir. Çocuk eğer ilkokula hazır değilse eğitim-öğretim yılının başlamasıyla ilkokullarda bulunan hazırlık sınıflarında bir sene süresince yoğun bir eğitim alır. Din dersi dışındaki derslerin tamamı sınıf öğretmeni tarafindan verilir. Sınıf öğretmeni birinci sınıfta öğrencilerin performansını değerlendirmeden önce, öğrenci ve velilerin katıldığı bir değerlendirme görüşmesi yapar ve çocuklar, öğrenim ve gelişim durumları hakkında birinci dönem sonunda ve öğretim yılı sonunda yazılı bilgi alırlar. İkinci sınıftan itibaren tüm öğrencilere notla yapılan bir değerlendirme üzerinden karne verilir. Dördüncü sınıfta, veliler çocuğun ilgi alanları ve performans düzeyine göre temel genel bir eğitim veren ve dört sene sürecek olan ortaokul (Mittelschule) veya kapsamlı ve geniş genel eğitim veren orta kısmı (Unterstufe) olan bir lise hakkında bilgilendirilir. İlkokuldan ortaokula geçiş için (Mittelschule, Unterstufe) dördüncü sınıfın başarıyla tamamlanması gerekir. (Stadt Wien-İlkokul, 2020; Stadt Wien-İlkokula Başvuru, 2020; Gratis-Kindergarten in Wien, 2020; Neue Vorgaben für Schuleinschreibungen, 2020, BMBWF, 2020a).

\section{Avusturya İlkokullarında Yabancılara Anadillerinin Öğretimi}

İlk dil, her insanın dil edinimi sürecinde merkezi bir rol oynar. Her çocuk dünyayı dil yardımıyla keşfeder ve düzenler. Bir çocuk okula başlaması sırasında Almancayı çok az biliyor veya hiç bilmiyor olsa bile yine de ilk dilinde yaşa uygun bir dil gelişimi gösterebilir. İlk dilde sağlam bir temel, sadece ikinci dilin (Almanca) edinilmesini desteklemekle kalmaz aynı zamanda diğer yabancı dilleri öğrenmenin yanı sıra okul başarısı ve çocuğun bilişsel gelişimi için de yararlı olur. Bu nedenle okulun, bir çocuğun iki dilliliğini mümkün olduğu ölçüde teşvik etmesi, çocuğun anadilinde iletişim kurabileceği öğretmenlerin varlığını hissetmesi, duygusal düzeyde çocuk üzerinde olumlu bir etki bırakacaktır. Bu sadece göçmen çocukların özgüvenlerini güçlendirmekle kalmaz, aynı zamanda okulla özdeşleşmelerini güçlendirir ve bu da öğrenme motivasyonunun artmasına katkıda bulunabilir (BMUKK, 2009).

Anadil öğretiminin Avusturya'da düzenli olarak okul sisteminin bir parçası olması üzerine 1992-1993 eğitim-öğretim yılı itibariyle Avusturya İlköğretim müfredat eğitim programları seçmeli dersler adı altında anadilinin öğretilmesi, Federal Eğitim, Bilim ve Araştırma Bakanlı̆̆ (BMBWF) tarafindan yayımlanan bir bildiride anadil dersleri hakkında bilinmesi gereken kanunlar ve yönetmelikler yer almıştır. Avusturya okullarında anadili Almanca olmayan öğrenciler ya da vatandaşlıklarına bakılmaksızın aile içerisinde iki dilde büyüyen öğrencilerin katılımıyla birlikte anadilin öğretilmesindeki amaç, geldikleri ülke ve ebeveynlerinin konuştukları dil ve kültür karşısında yaşadıkları ülke arasında kişilik ve aidiyet duygularının unutulmaması, iki kültürlülüğün, iki dilliliğin gelişimi ve pekiştirilmesi, anadilin genel eğitim sürecinde temel oluşturması ve diğer dillerin öğrenimini sağlamaktır (BMBWF, 2002; Muttersprachlicher Unterricht, 2003; Fleck, 2002). 
Avusturya ilköğretim okullarında 1972 y1lı itibariyle ülkeler arasında yapılan ikili görüşmeler çerçevesinde anadil dersleri göçmen öğrencilere ilk önce Sırpça-Hırvatça, Slovence ve Türkçe verilmeye başlanmış ve günümüzde ise öğrencilere 26 farklı dilde anadil dersleri verilmeye başlanmıştır. 26 farklı dilde verilen anadil dersleri arasında öğrencilerin en çok rağbet ettiği Arapça anadil dersi 2016-2017 eğitim ve öğretim yılından itibaren hep 3. sirada gelmektedir (BMBWF, 2020b).

Federal Eğitim, Bilim ve Araştırma Bakanlığınca Avusturya genelinde 2018-2019 eğitim ve öğretim yılı örgün eğitim kurumlarında anadil derslerine katılan öğrenciler hakkında en son yapılmış olan istatistiğe göre birinciliği Türkçe (149 öğretmen/12636 öğrenci), ikinciliği Boşnakça/Hırvatça/Sırpça (122 öğretmen/8870 öğrenci), üçüncülüğü ise Arapça (32 öğretmen/3129 öğrenci) almıştır. Anadili Almanca olmayan öğrenciler veya vatandaşlıklarına bakılmaksızın aile içerisinde iki dilde büyüyen 31173 öğrencilere 415 anadil öğretmenleri tarafından 26 farklı dil Arapça, Arnavutça, Bulgarca, Boşnakça/Hırvatça/Sırpça, Çeçence, Çekçe, Çince, Dari, Farsça, Fransizca, İgbo, İspanyolca, İtalyanca, Kürtçe (Kurmanci), Lehçe, Macarca Nepalce, Peştuca, Portekizce, Romence, Rumence, Rusça, Slovakça, Slovence, Somalice ve Türkçe- dil dersleri verilmiştir (BMBWF, 2012b).

Anadil öğretimi, aile içinde Almanca dışında bir veya daha fazla dil kullanan tüm öğrencilere yönelik olup dillerin sadece kısmen mi yoksa tamamen mi kullanılması önemli değildir. Anadil öğretimi müfredatı her bir dil için ayrı ayrı yapılandırılmamış, aksine herhangi bir dile uygulanabilecek kadar açık bir şekilde tasarlanmıştır.

Anadil öğretimi için öğretmenler Avusturya Milli Eğitim Müdürlükleri tarafından seçilir, işe alınır ve maaşı ödenir. Çoğu anadil öğretmeni dil eğitimlerini yurtdışında edindiği için genellikle bir yı1la sınırlı özel sözleşmelerle istihdam edilirler. 2007-2008 yılından itibaren bir öğretmenin on yıldan fazla ders vermesi halinde beş yıllık sözleşmeler yapılmaktadır. Anadilde eğitim gönüllülük esasına bağlı olup ilkokulda not vermeden bağlayıcı olmayan uygulamalı seçmeli bir ders olarak birinci sınıftan dördüncü sınıfa kadar haftada 2 saatle 6 saat arasında kurumsal açıdan mümkün olduğu sürece anadil dersi öğretmenleri ve sınıf öğretmenleriyle birlikte sınıflarda gerçekleştirilir. Ayrıca öğrencilerin sayıları az ise bu durumda farklı okul ve farklı sınıf seviyelerinden katılan öğrenciler birlikte gruplandırılarak anadil dersleri öğleden sonra işlenmektedir. Anadil derslerine katılan öğrencilerin dönem veya yıl sonu karnelerine katıldıklarına dair "katıldı" notu kaydedilir (BMBWF, 2002; Muttersprachlicher Unterricht, 2003; Fleck, 2002; BMBWF, 2012b; Lejri, 2010; Schulunterrichtsgesetz, 2020; Cinar, 1998).

\section{Avusturya İlkokullarında Arapça Anadil Dersleri}

Federal Eğitim, Bilim ve Araştırma Bakanlığı Avusturya genelinde 2018-2019 eğitim ve öğretim yılında anadil derslerine katılan öğrenciler hakkında yapmış olduğu istatistiğe göre Arapça anadil derslerine, Avusturya'nın dokuz eyaletinden sadece doğuda yer alan ve Macaristan ile Slovakya ülkelerine sınır olan "Burgenland" eyaleti dışında bütün diğer sekiz eyaletinde katılım sağlanmıştır. Arapça anadil derslerine kayıt yaptıran öğrenci sayısının az olması nedeniyle farklı okul ve sınıf düzeylerinden katılım sağlayan öğrenciler birlikte gruplandırılmış ve anadil dersleri öğleden sonra öğrencilere verilmiştir. Arapça anadil derslerine katılım sağlayan ilkokul öğrencilerinin sayısı 2273, ortaokul öğrencilerinin sayısı 570 ve diğer eğitim kurumlarında (lise vb.) okuyan öğrenci sayıs1 286 olmak üzere toplam 3129'dur. Bu öğrencilere 13 erkek 19 kadın öğretmen olmak üzere toplamda 32 öğretmen tarafından Arapça anadili dersi verilmiş̧ir. 32 öğretmenden ikisi Mısır, biri Fas, beşi Suriye, biri Tunus, yirmi üçü ise Avusturya vatandaşlığına sahip Arap kökenli kişilerden oluşmaktadır. Anadil dersleri veren öğretmenler ya Avusturya'da ya da geldikleri ülkelerinde öğretmenlik bölümünü bitirmiş olmaları gerekmektedir (BMBWF, 2020b; Pädagogische Hochschule Steiermark, 2020). 
2018-2019 eğitim ve öğretim yılında Kärnten eyaletinde Arapça anadil dersleri 11 ders saati olmak üzere 86 öğrenciye 1 öğretmen; Niederösterreich eyaletinde 26 ders saati olmak üzere 189 öğrenciye 3 öğretmen; Oberösterreich eyaletinde 27 ders saati olmak üzere 132 öğrenciye 1 öğretmen; Salzburg eyaletinde 24 ders saati olmak üzere 176 öğrenciye 3 öğretmen; Steiermark eyaletinde 35 ders saati olmak üzere 300 öğrenciye 2 öğretmen; Tirol eyaletinde 12 ders saati olmak üzere 72 öğrenciye 1 öğretmen; Vorarlberg eyaletinde 23 ders saati olmak üzere 211 öğrenciye 2 öğretmen; Wien eyaletinde ise 410 ders saati olmak üzere 1960 öğrenciye 19 öğretmen tarafindan verilmiştir (BMBWF, 2020b).

\subsection{Arapça Anadil Derslerinin Verildiği İlkokullar}

2018-2019 y1lında yapılan en son istatistiki verilere göre Arapça anadil dersleri, Kärnten eyaletine bağlı 3 ilkokulda, Niederösterreich eyaletine bağlı 12 ilkokulda, Oberösterreich eyaletine bağl1 7 ilkokulda, Salzburg eyaletine bağl1 8 ilkokulda, Steiermark eyaletine bağl1 11 ilkokulda, Tirol eyaletine bağl1 3 ilkokulda, Vorarlberg eyaletine bağl1 16 ilkokulda, Wien eyaletine bağlı 50 ilkokulda, toplamda ise 110 ilkokulda verilmiştir (Schulen mit muttersprachlichem Unterricht, 2020). Bu okulların isimleri ise şöyledir:

\section{* Kärnten eyaletine bağlı Villach șehri}

Volksschule, 9500 Villach, Khevenhüllergasse 16, Tel.: 042 42/ 285591

Volksschule, 9500 Villach, Trattengasse 3, Tel.: 042 42/ 2465211

Volksschule, 9500 Villach, Heidenfeldstraße 26, Tel.: 042 42/ 3354510

* Niederösterreich eyaletine bağlı Amstetten şehri

Volksschule, 3331 Kematen an der Ybbs, Kematen, 13.A Straße 3, Tel.: 074 48/ 3617

Volksschule, 4300 Sankt Valentin, Hauptplatz 9, Tel.: 074 35/ 52161

Volksschule, 3300 Amstetten, Elsa-Brandström-Straße 5, Tel.: 074 72/ 61630

- Niederösterreich eyaletine bağlı Baden şehri

Volksschule, 2540 Bad Vöslau, Raulestraße 6, Tel.: 022 52/ 71970

- Niederösterreich eyaletine bağlı Melk şehri

Volksschule, 3390 Melk, Dr.-Wilhelm-Reich-Straße 7, Tel.: 027 52/ 52610

- Niederösterreich eyaletine bağlı Neunkirchen şehri

Volksschule, 2620 Neunkirchen-Steinfeld, Dittrichstraße 12, Tel.: 026 35/ 62768

- Niederösterreich eyaletine bağlı Sankt Pölten-Land şehri

Volksschule, 3100 Sankt Pölten, Kerensstraße 13, Tel.: 027 42/ 3232311

Volksschule, 3100 Sankt Pölten, Grillparzerstraße 8, Tel.: 027 42/ 3232221

Volksschule, 3100 Sankt Pölten, Otto-Glöckel-Straße 1, Tel.: 027 42/ 363235

- Niederösterreich eyaletine bağlı Scheibbs şehri

Volksschule, 3250 Wieselburg, Schulstraße 5, Tel.: 074 16/ 52311

- Niederösterreich eyaletine bağlı Waidhofen an der Ybbs şehri

Volksschule, 3340 Waidhofen an der Ybbs, Plenkerstraße 8a, Tel.: 074 42/ 52476

- Niederösterreich eyaletine bağlı Wiener Neustadt-Stadt şehri

Volksschule, 2700 Wiener Neustadt, Baumkirchnerring 18, Tel.: 06 76/ 883732396

* Oberösterreich eyaletine bağlı Linz-Stadt șehri

Volksschule, 4020 Linz an der Donau, Volksfeststraße 7-11, Tel.: 07 32/ 778144

Turkish Studies - Language, 15(3) 
Volksschule, 4020 Linz an der Donau, Südtiroler Straße 13-15, Tel.: 07 32/ 662015

Volksschule, 4020 Linz an der Donau, Grillparzerstraße 49, Tel.: 07 32/ 65239618

Volksschule, 4020 Linz an der Donau, Wiener Straße 42, Tel.: 07 32/ 656016

Volksschule, 4033 Linz an der Donau, Resselstraße 8, Tel.: 07 32/ 307035

Volksschule, 4040 Linz an der Donau, Keplerstraße 11, Tel.: 07 32/ 732022

Volksschule, 4030 Linz an der Donau, Allendeplatz 1, Tel.: 07 32/ 305293

* Salzburg şehri merkez

Volksschule, 5020 Salzburg, Friedensstraße 13, Tel.: 06 62/ 621714

Volksschule, 5020 Salzburg, Nelkenstraße 5, Tel.: 06 62/ 433448

Volksschule, 5020 Salzburg, Pestalozzistraße 4, Tel.: 06 62/ 450230

Volksschule, 5020 Salzburg, Faberstraße 8, Tel.: 06 62/ 875274

Volksschule, 5020 Salzburg, Meierhofweg 4, Tel.: 06 62/ 879646

Volksschule, 5020 Salzburg, Billrothstraße 4, Tel.: 06 62/ 621044

- Salzburg eyaletine bağlı Hallein şehri

Volksschule, 5400 Hallein, Ferchlstraße 30, Tel.: 062 45/ 80216

- Salzburg eyaletine bağlı Zell am See şehri

Volksschule, 5700 Zell am See, Schulstraße 2 B, Tel.: 065 42/ 72513

* Steiermark eyaletine bağlı Graz şehri

Volksschule, 8020 Graz, Algersdorfer Straße 11, Tel.: 03 16/ 8726760

Volksschule, 8051 Graz-Gösting, Augasse 81, Tel.: 03 16/ 684929

Volksschule, 8020 Graz, Reiherstadlgasse 48, Tel.: 03 16/ 8726850

Volksschule, 8020 Graz, Grenadiergasse 1, Tel.: 03 16/ 712976

Volksschule, 8010 Graz, Brockmanngasse 119, Tel.: 03 16/ 830233

Volksschule, 8020 Graz, Am Fröbelpark 1-3, Tel.: 03 16/ 8727070

Volksschule, 8020 Graz, Lagergasse 41, Tel.: 03 16/ 8726750

- Steiermark eyaletine bağlı Judenburg şehri

Volksschule, 8750 Judenburg, Lindfeldgasse 7, Tel.: 035 72/ 82653

- Steiermark eyaletine bağlı Knittelfeld şehri

Volksschule, 8720 Knittelfeld, Gaalerstraße 7, Tel.: 035 12/ 82215

- Steiermark eyaletine bağlı Leoben şehri

Volksschule, 8700 Leoben-Leitendorf, Fröbelgasse 3, Tel.: 038 42/ 4062744

Volksschule/Sonderschule, 8700 Leoben, Kerpelystraße 13, Tel.: 038 42/ 4062746

* Tirol eyaletine bağlı Innsbruck şehri

Volksschule, 6020 Innsbruck, Wörndlestraße 3, Tel.: 05 12/ 344277

- Tirol eyaletine bağlı Landeck şehri

Volksschule, 6500 Landeck, Schulhausplatz 2, Tel.: 054 42/ 65347

- Tirol eyaletine bağlı Schwaz şehri

Volksschule, 6130 Schwaz, Franz-Josef-Straße 26, Tel.: 052 42/ 6950500 
Vorarlberg eyaletine bağlı Bludenz şehri

Volksschule, 6700 Bludenz, Bludenz-Mitte, Sankt-Peter-Straße 1, Tel.: 055 52/ 30980

Volksschule, 6714 Nüziders, Schulgasse 10, Tel.: 055 52/ 668286

Volksschule, 6780 Schruns, Jakob-Stemer-Weg 1, Tel.: 055 56/ 72435800

- Vorarlberg eyaletine bağlı Bregenz şehri

Volksschule, 6900 Bregenz, Augasse 6, Tel.: 055 74/ 4102710

Volksschule, 6900 Bregenz-Rieden, Mariahilfstraße 54, Tel.: 055 74/ 4102720

Volksschule, 6971 Hard, Seestraße 58, Tel.: 055 74/ 697610

Volksschule, 6952 Hittisau, Platz 406, Tel.: 055 13/ 242348

Volksschule, 6973 Höchst-Unterdorf, Gaißauer Straße 10, Tel.: 055 78/ 75485

Volksschule, 6911 Lochau, Landtstraße 28, Tel.: 055 74/ 44186

- Vorarlberg eyaletine bağlı Dornbirn şehri

Volksschule, 6850 Dornbirn, Schulgasse 42, Tel.: 055 72/ 22805

Volksschule, 6845 Hohenems, Kirchplatz 1, Tel.: 055 76/ 77166

Volksschule, 6890 Lustenau-Kirchdorf, Rathausstraße 9, Tel.: 055 77/ 81814340

- Vorarlberg eyaletine bağlı Feldkirch şehri

Volksschule, 6800 Feldkirch, Fidelisstraße 20, Tel.: 055 22/ 37377

Volksschule, 6807 Feldkirch-Tisis, Josef-Mähr-Straße 5, Tel.: 055 22/ 76757

Volksschule, 6822 Satteins, Schulplatz 5, Tel.: 055 24/ 8511

Volksschule, 6840 Götzis, Blattur 37, Tel.: 055 23/ 51602

* Wien eyaletine bağlı Leopoldstadt (2. Bölge)

Volksschule, 1020 Wien, Novaragasse 30, Tel.: 01/ 2147273

Volksschule, 1020 Wien, Schönngasse 2, Tel.: 01/ 7297179

Volksschule, 1020 Wien, Vereinsgasse 29, Tel.: 01/ 2143294

Volksschule, 1020 Wien, Vorgartenstraße 191, Tel.: 01/ 7263935

- Wien eyaletine bağlı Landstraße (3. Bölge)

Volksschule, 1030 Wien, Dietrichgasse 36, Tel.: 01/ 7145703

Volksschule, 1030 Wien, Kleistgasse 12, Tel.: 01/ 7986131

- Wien eyaletine bağlı Wieden (4. Bölge)

Volksschule, 1040 Wien, Waltergasse 16, Tel.: 01/ 5876216

- Wien eyaletine bağlı Margareten (5. Bölge)

Volksschule, 1050 Wien, Einsiedlergasse 7, Tel.: 01/ 5445710

- Wien eyaletine bağlı Josefstadt (8. Bölge)

Volksschule, 1080 Wien, Pfeilgasse 42b, Tel.: 01/ 4062642

- Wien eyaletine bağlı Alsergrund (9. Bölge)

Volksschule, 1090 Wien, Gilgegasse 12, Tel.: 01/ 4055433

Volksschule, 1090 Wien, Grünentorgasse 9, Tel.: 01/ 3195318 
- Wien eyaletine bağlı Favoriten (10. Bölge)

Volksschule, 1100 Wien, Quellenstraße 142, Tel.: 01/ 66020194

Volksschule, 1100 Wien, Jagdgasse 22, Tel.: 01/ 6065415

Volksschule, 1100 Wien, Knöllgasse 59, Tel.: 01/ 6040129

Volksschule, 1100 Wien, Neilreichgasse 111, Tel.: 01/ 6161560

- Wien eyaletine bağlı Simmering (11. Bölge)

Volksschule, 1110 Wien, Brehmstraße 9, Tel.: 01/ 7491446

Volksschule, 1110 Wien, Molitorgasse 11, Tel.: 01/ 7491707

Volksschule, 1110 Wien, Münnichplatz 6, Tel.: 01/ 762354

- Wien eyaletine bağlı Meidling (12. Bölge)

Volksschule, 1120 Wien, Haebergasse 1a, Tel.: 01/ 8158155

Volksschule, 1120 Wien, Johann-Hoffmann-Platz 20, Tel.: 01/ 8158178

Volksschule, 1120 Wien, Rothenburgstraße 1, Tel.: 01/ 8049105

Volksschule, 1120 Wien, Ruckergasse 42, Tel.: 01/ 8158179

Volksschule, 1120 Wien, Am Schöpfwerk 27, Tel.: 01/ 6676273

- Wien eyaletine bağlı Rudolfsheim-Fünfhaus (15. Bölge)

Volksschule, 1150 Wien, Friesgasse 10, Tel.: 01/ 8930096

Volksschule, 1150 Wien, Goldschlagstraße 14-16, Tel.: 01/ 9824609

Volksschule, 1150 Wien, Johnstraße 40, Tel.: 01/ 9822487

Volksschule, 1150 Wien, Selzergasse 19, Tel.: 01/ 9820706

Volksschule, 1150 Wien, Ortnergasse 4, Tel.: 01/ 8936403111

- Wien eyaletine bağlı Ottakring (16. Bölge)

Volksschule, 1160 Wien, Gaullachergasse 49, Tel.: 01/ 4060103

Volksschule, 1160 Wien, Brüsslgasse 18, Tel.: 01/ 4921049

Volksschule, 1160 Wien, Liebhartsgasse 19-21, Tel.: 01/ 4931587

- Wien eyaletine bağlı Hernals (17. Bölge)

Volksschule, 1170 Wien, Rötzergasse 2-4, Tel.: 01/ 4091220

- Wien eyaletine bağlı Währing (18. Bölge)

Volksschule, 1180 Wien, Klettenhofergasse 3, Tel.: 01/ 4064480

Volksschule, 1180 Wien, Schulgasse 57, Tel.: 01/ 4069989

- Wien eyaletine bağlı Döbling (19. Bölge)

Volksschule, 1190 Wien, Oskar-Spiel-Gasse 3, Tel.: 01/ 3702502111

Volksschule, 1190 Wien, Pantzergasse 25, Tel.: 01/ 3694245

- Wien eyaletine bağlı Brigittenau (20. Bölge)

Volksschule, 1200 Wien, Treustraße 55, Tel.: 01/ 3307561

Volksschule, 1200 Wien, Greiseneckergasse 29, Tel.: 01/ 3326349

Volksschule, 1200 Wien, Leystraße 34, Tel.: 01/ 3328552

Volksschule, 1200 Wien, Vorgartenstraße 95-97, Tel.: 01/ 3303152

www.turkishstudies.net/language 
Volksschule, 1200 Wien, Dietmayrgasse 3, Tel.: 01/ 3329127

- Wien eyaletine bağlı Floridsdorf (21. Bölge)

Volksschule, 1210 Wien, Dr.-Skala-Straße 43-45, Tel.: 01/ 2925350

Volksschule, 1210 Wien, Jochbergengasse 1, Tel.: 01/ 2922561

Volksschule, 1210 Wien, Mengergasse 33, Tel.: 01/ 2701168111

Volksschule, 1210 Wien, Pastorstraße 29, Tel.: 01/ 2596103

Volksschule, 1210 Wien, Priessnitzgasse 1/I, Tel.: 01/ 2782237

Volksschule, 1210 Wien, Priessnitzgasse 1-3/II, Tel.: 01/ 2700613

Volksschule, 1210 Wien, Adolf-Loos-Gasse 2, Tel.: 01/ 2568727

- Wien eyaletine bağlı Donaustadt (22. Bölge)

Volksschule, 1220 Wien, Meissnergasse 1, Tel.: 01/ 2032131

Volksschule, 1220 Wien, Mira-Lobe-Weg 4, Tel.: 01/ 2581198

\section{2. İlkokullarda Arapça Anadil Öğretiminin Hedefleri}

Arapça anadili öğretiminin hedefi, iki dilliliği geliştirmek ve pekiştirmekle beraber iki kültür arasında yaşayan öğrencilerin kişisel gelişimini ve kimlik oluşumunu desteklemektir. Bu hedefler doğrultusunda ilkokul 1. ve 2. sınıflarında beklenilen kazanımlar; okul öncesinde kazanılan dil becerilerinin korunması, sürdürülmesi ve geliştirilmesi, kavram oluşumunun geliştirilmesi, anadil ve Almanca da zıt yapılar hakkında temel bilgiler, iletişim becerilerinin genişletilmesi, menşe ülke hakkında temel bilgilerin verilmesi, iki kültürlü süreç üzerine düşünme ve inceleme, kültürlerarası projelerin uygulanması. İlkokul 3. ve 4. sınıflarında beklenilen kazanımlar ise; ilkokul 1.ve 2.sınıf düzeyinde edinilen dil becerilerinin korunması, sürdürülmesi ve geliştirilmesi, kelime dağarcı̆̆ının geliştirilmesi, anadil ve Almanca da zıt yapılar hakkında temel bilgiler, iletişim becerilerinin genişletilmesi, menşe ülke hakkında temel bilgilerin verilmesi, iki kültürlü süreç üzerine düşünme ve inceleme, kültürlerarası projelerin uygulanmasıdır (Volksschul-Lehrplan 2020).

\subsection{Arapça Anadil Dersleri Kayıtları, Okul Kitapları ve Öğretim Materyalleri}

Arapça anadil ders kayıtları diğer anadil dersleri gibi genellikle ilkokula ilk kayıt yapıldığı zaman veya bir sene sonraki katılım için 2. dönemin başlarında verilen kayıt günleri içinde tahsis edilen anadil ders kayıt belgeleri doldurularak veliler tarafından imzalı bir şekilde müdüriyete verilir. Bunun dışında kayıt tarihlerini kaçıran öğrencilerin ise tahsis edilen ders saatlerinin bölünmemesi koşuluyla kayıtları alınır. Arapça anadil derslerine katılacak öğrenci sayısının en az 10 olması gerekmektedir. Arapça anadil dersinde kullanılan ders kitapları ise Abdel-Rauf En-Najjar, Slimane Bou Chouicha, Chokri El-Hamrouni ve Fadhel Bedda tarafından Federal Eğitim, Bilim ve Araştırma Bakanlığı (BMBWF) bünyesinde hazırlanmış olup okul kitap listesinden anadil dersi öğretmenleri vasıtasıyla öğrenciler için parasız temin edilir. Ders kitaplarının yanı sıra anadil derslerine katılan her bir öğrenciye Arapça-Almanca bir sözlük de dağıtılır. Anadil dersi öğretmenleri Arapça ders kitaplarının yanı sıra kendi imkanları ile aldıkları eğitim kitapları, hazırladıkları eğitim materyallerini de derslerinde kullanmaktadırlar (BMBWF, 2002; Muttersprachlicher Unterricht, 2003; Demir\&Karakrök, 2016; Fleck, 2002; BMBWF, 2012b; Lejri, 2010; Schulunterrichtsgesetz, 2020).

- Illkokul 1. sınıf öğrenciler için kullanılan Arapça Kitabı: (1 العربية الميسرة_القراءة والتمارين). Kolay Arapça-Okuma ve Alıştırmalar 2. Editions Granada, 2008 (6 yaş+110 sayfa).

Kitap 105 sayfadır. Kitabın kapak sayfasında bulunan (Common European Framework of Reference for Languages) amblemi ile kitabın Avrupa Dilleri Ortak Çerçeve Programına göre hazırlandığı anlaşılmaktadır. Kitap 14 üniteden oluşmaktadır ve her ünite kendi içerisinde Arap alfabesinde bulunan 28 harfe göre şekillendirilmiştir. Her ünite kendi içerisinde dört temel dil 
becerisine yönelik etkinlikler içeren (okuma, anlama, yazma ve dinleme) kısa bölümlerden oluşmaktadır. Ünitelerin sonunda ise alıştırmalar verilmiştir. Üniteler başlamadan önce ünite içerisinde yer alacak harfi gösteren tanıtıcı büyük bir resim bulunmaktadır. Her harf imla kurallarına göre nasıl yazıldığını gösteren resimlerle birlikte harf ve kelimelerle boşluk doldurma, resimlerin altlarında verilen kelimelerin tamamlanması, kelimelerin resimlerle birleştirilmesi, zıt kelimelerin bulunması gibi alıştırmalarla da desteklenmiştir.

- İlkokul 2. sınıf öğrenciler için kullanılan Arapça Kitabı: (العربية الميسرة_القراعة والتمارين 2) Kolay Arapça-Okuma ve Alıştırmalar 2. Editions Granada, 2008 (7 yaş+78 sayfa).

Kitap 78 sayfadır. Kitabın kapak sayfasında bulunan (Common European Framework of Reference for Languages) amblemi ile kitabın Avrupa Dilleri Ortak Çerçeve Programına göre hazırlandığı anlaşılmaktadır. Kitap 12 üniteden oluşmaktadır ve üniteler ya bir diyalog ya da bir hikâye ile başlıyor. Verilen okuma parçalarında geçen fiillerin açılanmasıyla birlikte geçmiş zaman, şimdiki zaman ve emir kiplerinden oluşan cümleler ve alıştırmalar yer almaktadır. Üniteler içerisinde verilen sorulara cevaplar istenmekte olup resimlerle desteklenmiş̧tir. Bununla birlikte soru edatları, sıfatlar, ismin halleri, tekil-çoğul ve zarflar öğretilmeye çalış1lmıştır.

- İlkokul 3. sınıf öğrenciler için kullanılan Arapça Kitabı: (3 العربية الميسرة-القراءة والتمارين). Kolay Arapça-Okuma ve Alıştırmalar 2. Editions Granada, 2008 (8 yaş+91 sayfa).

Kitap 91 sayfadır. Kitabın kapak sayfasında bulunan (Common European Framework of Reference for Languages) amblemi ile kitabın Avrupa Dilleri Ortak Çerçeve Programına göre hazırlandığı anlaşılmaktadır. Kitap 12 üniteden oluşmaktadır. Her ünite eğitici bir hikâye ile başlıyor. Hikayelerde geçen önemli kelimeler açıklanıp eş anlamlarına yer verildiği gibi gelecek zaman, olumsuzluk veren edatlar, fiil çeşitleri, fiil çekimleri, işaret zamirleri, iyelik zamirleri, eril ve dişiliği gösteren alametler de yer almıştır. Üniteler sonunda verilen alıştırmalarda soru-cevap, boşluk doldurma, harflerin birleştirilmesi, doğru-yanlış gibi egzersizlerle Arapça dilbilgisi öğretilmeye çalışılmıştır.

- IIlkokul 4. sınıf öğrenciler için kullanılan Arapça Kitabı: (4 العربية الميسرة_القراءة والتمارين). Kolay Arapça-Okuma ve Alış̧ırmalar 2. Editions Granada, 2008 (9 yaş+91 sayfa).

Kitap 91 sayfadır. Kitabın kapak sayfasında bulunan (Common European Framework of Reference for Languages) amblemi ile kitabın Avrupa Dilleri Ortak Çerçeve Programına göre hazırlandığı anlaşılmaktadır. Kitap 12 üniteden oluşmaktadır. Her ünite bir hikâye ile başlıyor. Hikayelerde geçen önemli kelimeler açıklanıp eş anlamlarına yer verildiği görülmektedir. Alıştırmalarda hikâyeye yönelik sorulara cevap verme, eşleştirme, boşluk doldurma, cümle tamamlama, verilen resimleri betimleme, özne-fiil-nesne ilişkisi, tamlama, belirleyici ön ekler, isimfiil gibi Arapça dilbilgisi öğretilmeye çalışılmıştır.

\subsection{Arapça Anadil Derslerine Katılan Öğrenciler}

Arap kökenli öğrencilerin ebeveynlerinin farklı Arap ülkelerinden (Fas, Filistin, Kuveyt, Libya, Mısır, Sudan, Suriye, Tunus) olması sebebiyle Arapça anadil derslerine katılan öğrenciler evlerinde fasih Arapça yerine kendi ülke lehçelerini konuşmaktadırlar. Okula geldiklerinde ise fasih Arapça öğrenmektedir. Öğrenci sayısının az olması nedeniyle tayin edilen merkezi bir ilkokulda toplu Arapça dersleri öğleden sonra verilmektedir. Öğleden sonra verilen Arapça derslere katılım sağlayan öğrencilerin yaşları 6-10 yaş arasında olup yeni başlayanlar ve ileri düzeyde olanlar arasında sınıflandırılarak gruplar oluşturulmaktadır. Birçok veli, çocuklarını derse katılım sağlamalarından dolayı çeşitli şekilde ödüllendirmektedir. Arapça anadil derslerinde, öğrencilerin yaşlarına uygun kelime dağarcığının oluşturulması, iletişim becerilerinin geliştirilmesi, okumayazma becerilerinin kazandırılması, dil bilgisi ve imla konularının da öğretilmesiyle birlikte ögrencilerin öğrendikleri fasih Arapçayla basılı medyayı takip edebilecek, kitap okuyabilecek ve 
Arapça metinler yazabilecek bir konuma gelmesi sağlanarak kültürel kimliğin oluşturulmasına yardımcı olunmaktadır. Farklı lehçelere sahip olan öğrenciler okulda birbirleriyle Arapça konuşmazlar. Çünkü lehçeler arasındaki fark, iletişimi zorlaştırır veya imkânsız hale getirebilir. Bundan dolayı fasih Arapça günlük konuşma dili olarak kullanılmadığından, öğrenciler iletişim dili olarak teneffüslerde, öğleden sonraki etütlerde ve okul dışı aktivitelerde Almanca konuşmaları hatta çocukların evde ebeveynleriyle Arapça konuşmalarına rağmen kardeşleriyle Almanca konuşmayı tercih ettikleri gözlemlenmiştir. Derse katılan öğrencilerin velileri, çocuklarının akrabalarla iletişim kurarak geleneklerinin devamının sağlanmasını ve anadilde okuma ve yazma becerilerinin ilerlemesiyle kimliklerinin güçlenerek çocuklarının daha sağlam, daha güvenli ve hoşgörülü bireyler olmasını istemektedirler (Lejri, 2010; Khan-Svik 2005).

\section{Sonuç}

Betimleyici araştırma ve literatür taraması yönteminin kullanıldı̆̆ı bu çalışmada, Avusturya devleti dil politikaları çerçevesinde Avusturya ilkokullarında ikinci dil ediniminin (Almanca) önemine binaen, Arap kökenli öğrencilere verilen Arapça anadil dersleri incelenmiştir. Avusturya vatandaşı veya Arap göçmen çocukların kendilerine özgüven duymaları, bir kişilik ve kimlik oluşumunun geliştirilmesi, gelmiş oldukları ülkelerin kültürel özelliklerini özümseyerek daha sağlam bir yapıya dönüştürme imkânını bulabilmeleri için, Arapça anadil derslerine katılmaları sağlanmaya çalış1lmıştır.

Arapça anadil öğretimi 1990'lı yıllarda uygulanmaya başlanmış ve zamanla Avusturya'nın sekiz eyaletinde bulunan eğitim kurumlarında yaygınlaşmıştır. En son istatistiki verilere göre 26 farklı anadil dersleri arasında Türkçe birinciliği, ikinciliği Boşnakça/Hırvatça/Sırpça üçüncülüğü ise Arapça almıştır. Arapça anadil derslerine katılım sağlayan ilkokul öğrencileri 2273, ortaokul öğrencileri 570 ve diğer eğitim kurumlarında (lise vb.) okuyan 286 öğrenci olmak üzere toplamda 3129 öğrenciye, 13 erkek öğretmen ve 19 kadın öğretmen olmak üzere toplamda 32 ögretmen tarafından Arapça anadili dersi verilmiştir. 32 öğretmenden ikisi Mısır, biri Fas, beşi Suriye, biri Tunus, yirmi üçü ise Avusturya vatandaşlığına sahip Arap kökenli kişilerden oluşmaktadır.

Arapça anadil dersleri, Kärnten eyaletine bağlı 3 ilkokulda 11 ders saati olmak üzere 86 öğrenciye 1 öğretmen, Niederösterreich eyaletine bağlı 12 ilkokulda 26 ders saati olmak üzere 189 öğrenciye 3 öğretmen, Oberösterreich eyaletine bağl1 7 ilkokulda 27 ders saati olmak üzere 132 öğrenciye 1 öğretmen, Salzburg eyaletine bağlı 8 ilkokulda 24 ders saati olmak üzere 176 öğrenciye 3 öğretmen, Steiermark eyaletine bağlı 11 ilkokulda 35 ders saati olmak üzere 300 öğrenciye 2 öğretmen, Tirol eyaletine bağlı 3 ilkokulda 12 ders saati olmak üzere 72 öğrenciye 1 öğretmen, Vorarlberg eyaletine bağl1 16 ilkokulda 23 ders saati olmak üzere 211 öğrenciye 2 öğretmen, Wien eyaletine bağl1 50 ilkokulda 410 ders saati olmak üzere 1960 öğrenciye 19 öğretmen verilmiştir.

Avusturya ilkokullarında verilen Arapça anadili öğretiminin entegrasyon ve kimlik oluşumuna yardımcı olması ve iki kültürlülügün gelişimi, iki dilliliğin gelişmesi ve pekiştirilmesi için çaba gösterilmiştir.

\section{Kaynakça}

Archan, Sabine ve Thomas, Mayr (2006). Berufsbildung in Österreich Kurzbeschreibung. Cedefop Panorama series; 124. Luxemburg: Amt für amtliche Veröffentlichungen der Europäischen Gemeinschaften

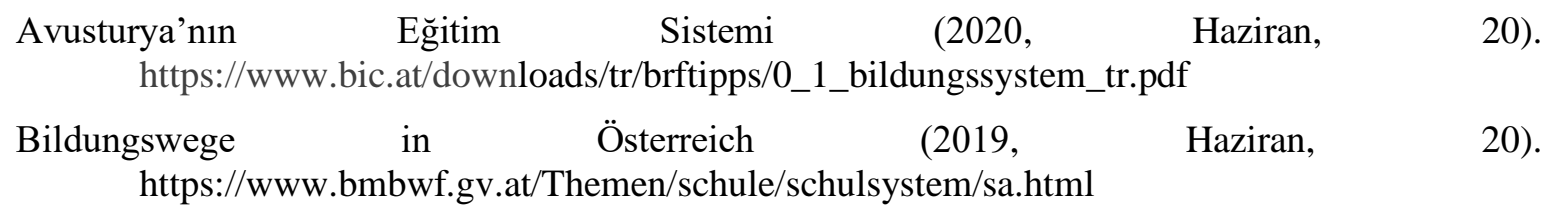


BMBWF (2002, May1s, 20). https://www.yumpu.com/de/document/read/21729689/den-erstenschritt-gehen-wir-gemeinsam-bundesministerium-fur-

BMBWF (2012a, Haziran, 20). https://www.schulemehrsprachig.at/fileadmin/schule_mehrsprachig/redaktion/hintergrundinfo/info1-12.pdf

BMBWF, (2012b). Gesetzliche Grundlagen schulischer Maßnahmen für SchülerInnen mit anderen Erstsprachen als Deutsch - Gesetze und Verordnungen, 16. aktualisierte Auflage

BMBWF (2020a, Haziran, 20). https://www.bmbwf.gv.at/Themen/schule/schulsystem/sa/vs.html

BMBWF (2020b). Informationsblätter zum Thema Migration und Schule. Der muttersprachliche Unterricht in Österreich Statistische Auswertung für das Schuljahr 2018/19, Nr. 5/2020, 21. aktualisierte Auflage,

BMUKK (2009). Informationsblätter des Referats für Migration und Schule. Der muttersprachliche Unterricht in Österreich. Zehnjahresübersicht für die Schuljahre 1998/99 bis 2007/08.

Cillia, Rudolf (2006). Spracherwerb in der Migration; In: Bundesministerium für Bildung, Wissenschaft und Kultur: Informationsblätter des Referats für Interkulturelles Lernen, Nr. 3, 9. aktualisierte Auflage.

Cillia, Rudolf (1998). Mehrsprachigkeit und Herkunftssprachenunterricht in europäischen Schulen, In: Cinar, Dilek (Hrsg.) (1998): Gleichwertige Sprachen? Muttersprachlicher Unterricht für die Kinder von Einwanderern; Forschungsbericht des BMUK, Studien Verlag, 229-288.

Cinar, Dilek (1998). Gleichwertige Sprachen? Muttersprachlicher Unterricht für die Kinder von Einwanderern; Forschungsbericht des BMUK, Studien Verlag.

Cinar, Dilek ve Davy, Ulrike (1998): Von der Rückkehrförderung zum Interkulturellen Lernen: Rahmenbedingungen des muttersprachlichen Unterrichts. In: Gleichwertige Sprachen? Muttersprachlicher Unterricht für die Kinder von Einwanderern. Studien Verlag, 23-80.

Das österreichische Schulsystem (2020, https://www.bmbwf.gv.at/Themen/schule/schulsystem.html

Haziran,

20).

Demir, Hüseyin\&Karakök, Tunay (2016). Der muttersprachliche Türkischunterricht im islamischen Realgymnasium in Wien. Journal of History School (JOHS), say1: 28, s. 393 - 405. DOI No: http://dx.doi.org/10.14225/Joh1013

Fleck, Elfie (2002, Haziran, 20). Der muttersprachliche Unterricht. http://www.bmukk.gv.at/medienpool/16066/mutt_unterr_fleck.pdf

Gratis-Kindergarten in Wien (2020, Haziran, 20). https://www.wien.gv.at/bildung-forschung/gratiskindergarten.html

Grosse, Ingrid (2000). Die Bedeutung der Muttersprachenförderung für denZweitspracherwerb, Eine Untersuchung zur Deutschkompetenz von Migrantenkindern aus Ex-Jugoslawien und der Türkei. Diplomarbeit Universität Wien.

Guus ve Yağmur, (2013, Haziran, 20). Dil Zengini Avrupa Avrupa'da Çokdillili Politika ve Uygulama Ĕ̈ilimleri. https://www.teachingenglish.org.uk/sites/teacheng/files/LRE_Turkish_Dil_Zengini_Avrup a_\%E2\%80\%93_Avrupa\%E2\%80\%99da_c\%CC\%A7okdilli_politika_ve_uygulama_eg\% CC\%86ilimleri.pdf

Khan-Svik, Gabriele (2005): Muttersprachliche Bildungseinrichtungen in Wien. In: Erziehung \& Unterricht, 1-2/2005, öbv\&hpt Verlag, 116-178. 
Lehrplan der Volkschule, (2012, Haziran, 20). https://www.bmbwf.gv.at/dam/jcr:fde2450 a-10f541ca-8e17-b99fae8d7b90/medien_lp_vs_25727.pdf

Lejri, Raoudha (2010). Muttersprachlicher Arabisch-Unterricht an Pflichtschulen in Wien. Diplomarbeit, Universität Wien.

Muttersprachlicher Unterricht, (2003, Haziran, 20). https://www.bmbwf.gv.at/dam/jcr:af8 97cab0437-4a9f-b47f-afbb8aaa0293/VS9T_Muttersp_3937.pdf

Neue Vorgaben für Schuleinschreibungen (2020, Haziran, 20). https://www.vienna.at/neuevorgaben-fuer-schuleinschreibungen/6483400

Pädagogische Hochschule Steiermark, (2020, Temmuz, 20). https://bimm.at/muttersprachlicherunterricht-erstsprachen-unterrichten-im-kontext-von-migration/

Stadt Wien-İlkokul (2020, Haziran, 20). https://www.wien.gv.at/tr/egitim/okulsistemi/ilkokul/

Stadt Wien-İlkokula Başvuru (2020, Haziran, 20$)$. https://www.wien.gv.at/tr/egitim/okulsistemi/ilkokul/basvuru.htm

Schulunterrichtsgesetz,

$(2020$,

Haziran,

20). https://www.ris.bka.gv.at/GeltendeFassung.wxe?Abfrage=Bundesnormen \&Gesetzesnumm er $=10009600$

Schulen mit muttersprachlichem Unterricht, (2020, Haziran, 20). http://www.schulemehrsprachig.at/fileadmin/schule_mehrsprachig/redaktion/muttersprachlicher_unterricht/1 91001_schulliste18-19_mu.pdf

Volksschul-Lehrplan $(2020$,

Haziran, 20). https://www.bmbwf.gv.at/Themen/schule/schulpraxis/lp/lp_vs.html\#heading Freigegenstaende_und_unverbindliche_Uebungen 